\title{
A COMPARATIVE PROSPECTIVE CLINICAL STUDY OF EFFICACY OF PLATELET-RICH FIBRIN (PRF) AND CHLORHEXIDINE GEL FOR WOUND HEALING ENHANCEMENT AND PREVENTION OF ALVEOLAR OSTEITIS
}

\author{
Sayed A. Rashed
}

\begin{abstract}
Objective: The purpose of this research was to compare the effectiveness of intra-alveolar platelet rich fibrin (PRF) and chlorhexidine gel for pain relief and quality of socket healing (Epithelialization) with prevention of dry socket after the surgical removal of impacted third molars.

Patients and methods: A total of 30 patients (17 males and 13 females; with a mean age of 30 years). who required extraction of impacted third molars were randomly divided into three groups: PRF group ; PRF were placed in the extraction sockets ,chlorhexidine CHX gel 0.2\% group ; $1 \mathrm{ml}$ CHX were placed in the extraction sockets and control group, while the sockets remained empty. All the patients were evaluated for Pain (VAS), degree of inflammation, healthy granulation tissue formation and number of exposed socket walls (socket epithelialization), dry socket incidence and maximum interincisal mouth opening MIO at $1^{\text {st }}, 3^{\text {rd and }} 7^{\text {th }}$, post-operative day.
\end{abstract}

Results: In the PRF group, a significantly less pain was recorded in the third and seventh postoperative days $(P=0.003,0.04)$ respectively. Group $(P R F)$ showed better soft tissue and socket healing than chlorhexidine gel and control groups but non-significant difference was observed. PRF reduced the incidence of alveolar osteitis. .

Conclusion: PRF in this study illustrates the promising results to be used effectively in the prevention of alveolar osteitis. PRF treated cases showed better response to postoperative pain, better clinical socket healing with reduction of inflammation and more improvement of maximum interincisal mouth opening MIO than chlorhexidine gel $0.2 \%$ after the removal of third molars.

KEY WORDS: alveolar Osteitis, Dry socket, (PRF), Third molar surgery, chlorhexidine gel.

\section{INTRODUCTION}

Pathway of alveolar socket healing is divided into three overlapping phases, the inflammatory, proliferative, and remodeling stages. During the inflammatory stage, blood clot is formed and numerous inflammatory cells migrate to the socket. A granulation tissue is then formed by angiogenesis

\footnotetext{
* Lecturer, Department of Oral and Maxillofacial Surgery, Faculty of Dentistry, Ahram Canadian University.
} 
and the migration of immature fibroblasts. In the proliferative stage, the granulation tissue becomes rich in collagen fibers and cells, which provide a connective tissue matrix for rapid tissue formation. In this stage, several vessels and osteogenic cells are present and woven bone formation is initiated. In addition, the oral epithelial cell migration begins from the marginal gingiva to form the epithelial coverage. During the bone remodeling stage, the woven is replaced with lamellar bone and bone marrow. Choukroun et al. ${ }^{3}$ indicated that the most important aspects of healing include angiogenesis, immunity, the recruitment of circulating stem cells, and wound protection by epithelial coverage. ${ }^{1-3}$

Angiogenesis is one of the essential processes during wound healing. It is responsible for providing immunity as well as the regenerative cells, nutrition, and oxygen needed for the healing of the alveolar socket following tooth extraction. The healing process of extraction socket is affected by multiple local or systemic factors. The inappropriate removal of formed blood clots causes alveolar osteitis (AO) or dry socket. It is beneficial if strategies for preventing $\mathrm{AO}$ are directed toward more proangiogenic materials and modalities. Acute alveolar osteitis (AO) is one of the most common postoperative complications following teeth extraction. AO causes a sharp pain so temporarily reducing the quality patients of life - prevention remains the main therapeutic shield, there have been significant efforts to achieve an effective protocol aimed to reduce the prevalence of the alveolar osteitis. alveolar osteitis (AO) was defined by Blum ${ }^{4}$ as "The presence of postoperative pain in and around the site of extraction which increases in severity between 1 and 3 days after the extraction, accompanied by a partially or totally disintegrated blood clot within the alveolar socket, with or without halitosis. ${ }^{5-8}$

Exact etiology of AO is not fully clarified, but the fibrinolysis of the the blood clot as a result of bacterial invasion is the most common cause. It has been theorized that traumatic extraction or the presence of a bacterial infection hastens the release of plasminogen tissue activators resulting in the plasmin induction of fibrinolysis that disintegrates blood clot leading to alveolar osteitis. Alveolar osteitis AO has been considered a socially significant disorder as it requires extra time for its treatment. Majority of intervention for $\mathrm{AO}$ focus on prevention rather than treatment. Current preventive measures include anti-inflammatory agent, clot support agent, topical antibiotics, chlorhexidine, and tranexemic acid have been proposed to assist in the prevention of AO. Antiseptics such as chlorhexidine have proved to be efficient in $\mathrm{AO}$ prevention. Utilization of $0.2 \%$ chlorhexidine bioadhesive gel has resulted in new lines of research in dry socket prevention. Recently, good results have been reported, with using PRF, for prevention of dry socket after removing lower third molars. ${ }^{9-12}$

Platelet-rich fibrin (PRF) is considered as a revolutionary step in regenerative dentistry. The use of platelet concentrates for the improvement of soft and hard tissues regeneration has been reported. Platelet-rich fibrin (PRF) a second- generation aggregate was developed in 2001 in France by Prof. Dr. Joseph Choukroun $^{3}$ which prepared by a simple procedure without need for anticoagulant factors. It has regenerative properties and considered as autologous source for growth factors which are important in tissue restoration and wound healing. PRF is an autologous fibrin matrix rich in platelets, leucocytes and monocytes that induce a cascade of multiple growth factors release. The PRF clot is achieved through a natural polymerization process during centrifugation and its natural and stable fibrin matrix is responsible for tissue regeneration. ${ }^{13-17}$

There are assorted opinions regarding chlorhexidine $\mathrm{CHX}$ as an effective preventative measure of $\mathrm{AO}$. The emerge of $0.2 \% \mathrm{CHX}$ in the form of a bioadhesive gel has resulted in new lines 
of research in $\mathrm{AO}$ prevention. Chlorhexidine gel can be placed within the alveolus, enabling a more direct and prolonged action on the socket. Chlorhexidine gel could be applied as a prophylactic approach, especially in patients with high risk of developing dry to aid in reducing the risk of dry socket development. Although a significant reduction in dry socket incidence has been detected when using the CHX gel however a recent study, reported that there was relative risk of developing dry socket in sockets received chlorhexidine gel. The placement of $\mathrm{CHX}$ gel in an intra-alveolar fashion could potentially have an adverse effect on the clotting formation process within the surgical site. The local placement of the gel could interfere mechanically with the clot formation process. ${ }^{18-22}$

There was an attention for a novel application of PRF in extraction sockets. This present prospective clinical research was designed to assess and compare the effectiveness of PRF and chlorhexidine gel placed directly into the surgical socket after removal of the mandibular third molar on acceleration of tissue healing and reducing potential postoperative complications, pain, trismus and the rate of alveolar osteitis

\section{PATIENTS AND METHODS}

This study was done on thirty patients (17 male and 13 female) who required the removal of impacted third molars with difficulty score between 7 and 10 on the basis of Pederson difficulty index ${ }^{23}$ were included in the study. Patients were treated at the Department of Oral and maxillofacial Surgery, Dental College, Ahram Canadian University. After obtaining approval from the ACU research and ethical committee, both genders, between 18 and 47 years were enrolled in this study. Exclusion criteria included conditions such as pregnancy, immunocompromised disorders, smokers, diabetics and patients on steroid therapy. Those patients with incomplete follow-up were excluded from the study.
After obtaining the history of each case, patients were clinically examined. Then, the procedure for the treatment, its complications, and follow-up period was explained to patients. Patients joined for the study signed written consent. Preoperative and postoperative panoramic $\mathrm{x}$-ray view and intraoral periapical (IOPA) radiographs were taken. The patients were randomly distributed into three groups, each consisting of 10 patients (sample size $=10 /$ group): - PRF -treated group: Comprised patients having extraction socket filled with PRF before closure of the socket (Fig. 1). $\bullet$ Chlorhexidine gel 0.2-treated group: Comprised patients having an extraction socket filled with CHX before closure of the socket (Fig. 2). - Control group: Involved patients having an extraction socket closed without any dressing.

\section{Surgical procedure}

Surgical removal of mandibular third molars was done under local anesthesia (using 2\% mepivacaine hydrochloride with 1:20,000 levonordephrine) (Alexandria Company for Pharmaceuticals and Chemical Industries, Alexandria, Egypt.) in atraumatic manner Figure 1. A triangular fullthickness flap has been raised; buccal guttering was done using a surgical carbide bur. the socket was irrigated with 0.9 saline after removal of the tooth and achieving hemostasis. Before suturing of the mucoperiosteal flap incorporation of PRF or chlorhexidine gel $0.2 \%$ within the socket was done in the study groups. Platelet-rich fibrin buffy was applied in the extraction socket within 15 minutes after preparation and secured in position with sutures as in Figure $2 \mathrm{~B}$ and C. All extraction sockets (control and study groups) were sutured with a $3 / 0$ black silk suture. pharmacological treatments were the same for three groups; antibiotics Amoxicillin $500 \mathrm{mg} 4$ times/day for five days(Biomox, Sedico Company), analgesics (paracetamol 500 mg, ADWIC Company) for 3 days with regular instructions. Outcomes were assessed for control and study groups. Evaluation was done at 1st, 
3rd and 7th day after extraction, all the procedures were done comfortably under local anesthesia on an outpatient basis without complication except one case of CHX group who suffered from lip numbness that vanish within two weeks. On 1st, 3rd and 7th post-operative day: The patients were evaluated for signs of dry socket, pain, inflammation, and restriction in mouth opening (trismus).

\section{Method of preparation of platelet-rich fibrin}

PRF preparation was performed according to Dohan ${ }^{13}$. The procedure was explained to the patients. Also, the patients were informed about the accidents of phlebotomy, hematoma, edema, or the doctor can't find the vein. The area of the anticubital region was prepared with alcohol wipes and $10 \mathrm{ml}$ of blood for two tubes was drawn from the patients' cephalic or basilic veins using a safety blood collection set+ Luer adapter (Greiner BioOne GmbH, Austria) (Fig. 1B). The blood was then transferred to a centrifugal vial without any anticoagulant and centrifuged immediately using a tabletop centrifuge for 12 minutes at $2700 \mathrm{rpm}$. The resultant product consists of three layers :(1)

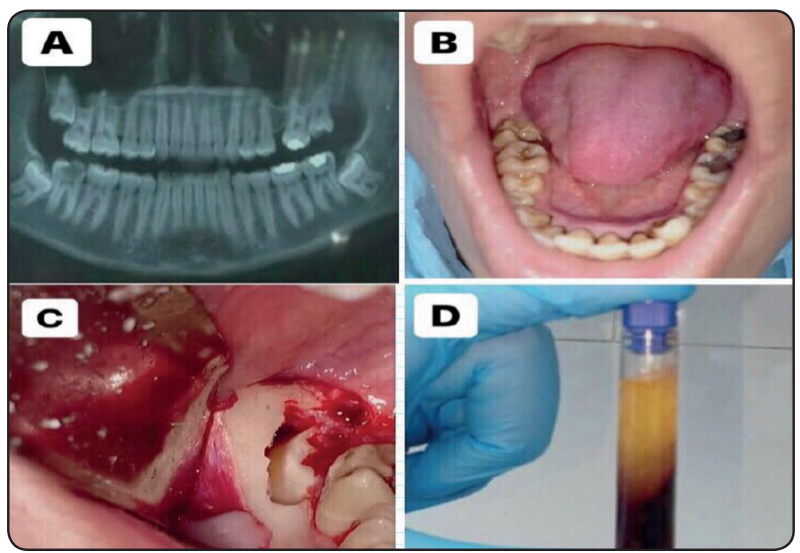

Fig. (1) A. preoperative panoramic $\mathrm{x}$ ray view of bilateral impacted lower wisdom B. Preoperative clinical photograph C. buccodistal guttering D. PRF clot in middle of centrifuge vial
Topmost layer consisting of acellular plasma (platelet poor plasma) (2) PRF clot in the middle which it is used clinically and (3) Red Blood Cells at the bottom that are discarded (Fig. 1D)(Fig. 2A).

\section{Intra-alveolar PRF Application}

PRF clot was withdrawn from the centrifugal vial using Adson forceps. Most of the attached red blood cell was removed from the bottom of the PRF using scissors, and then the PRF plug was condensed using special PRF processing box (Nichrmnox Co.) to squeeze serum out of the Platelet-rich fibrin clot as described by Dohan ${ }^{13,14}$. The PRF plug was then placed in the socket then suturing was done (Fig 2).

\section{Intra-alveolar Chlorhexidine Gel 0.2\% Application}

After the operation a chlorhexidine bioadhesive gel $0.2 \%$ (Sigma-Aldrich, st.loais, USA) was applied to same-sized dressings of gelatin sponge (Catanplast, Mascia Brunelli S.P.A., Italy). Impregnated dressing was pushed gently into the sockets. It was made sure that they had reached the socket floors and that there was no observable excess material.
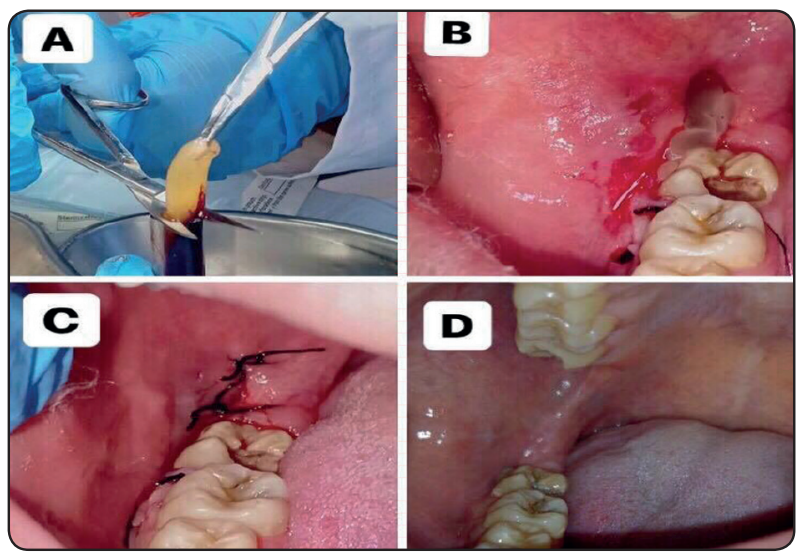

Fig. (2) A. Segregation of PRF plug B. PRF placement in extracted socket C. black silk suture closure D. One week postoperative healing 

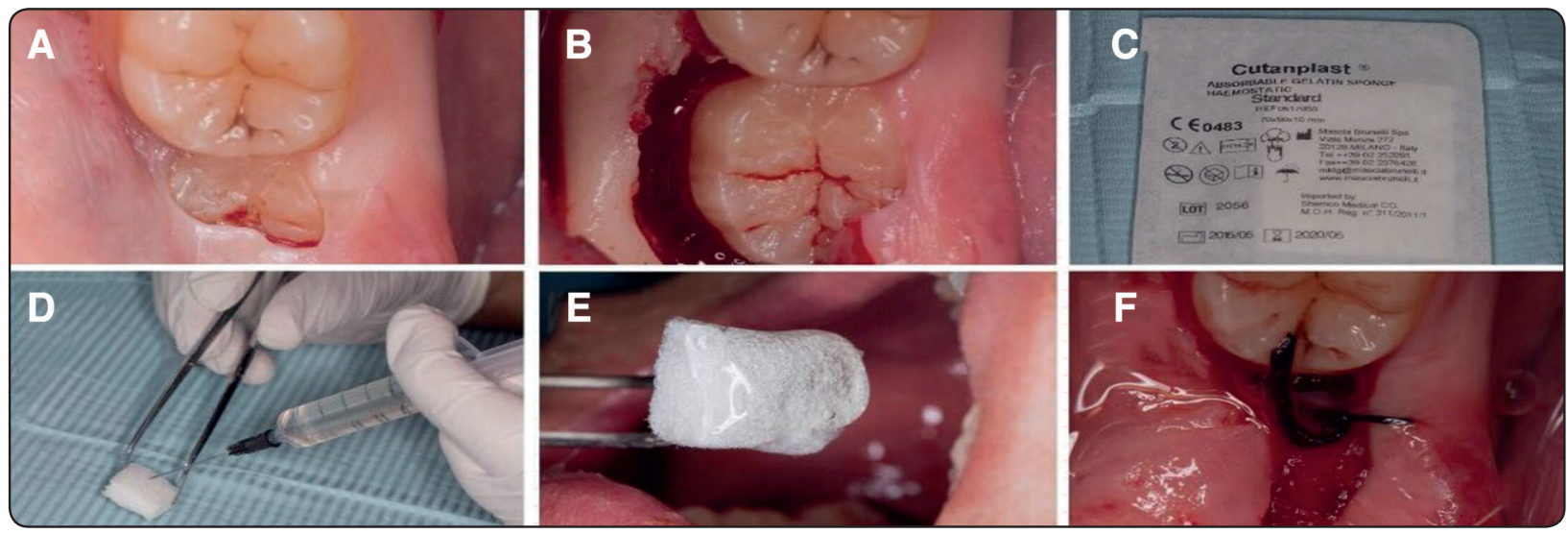

Fig. (3) A. Preoperative photo of impacted lower wisdom. B. Surgical guttering. C. Absorbable gelatin sponge. D. Impregnation of CHX gel with gelatin sponge. E. CHX dressing placement. F. CHX gel with gelatin sponge in socket

\section{Postoperative monitoring and variables}

Pain: The subjective feeling of pain assessment based on visual analogue scale VAS which was recorded from score 0 (no pain) to score 10 which revealed (worst pain) which was completed by the patient. The pain was evaluated post-operatively at day 1,3 , and 7 .

\section{Socket healing and Granulation tissue} formation: Clinical examinations of socket healing were performed on $1^{\text {st }}$, $3 \mathrm{rd}$, and $7^{\text {th }}$ day and assessed by the the number of exposed socket walls. Evaluation of soft tissue healing was based on the standard method. ${ }^{24}$ socket treated with PRF, Chlorhexidine gel and control groups were assessed clinically by the coverage of the exposed bone by soft granulation tissue formation and socket epithelialization which can be graded as: 0 - no bony walls exposed, 1 - only one bony wall exposed, 2 - two bony walls exposed, 3 - three bony walls exposed, and 4 - four bony walls exposed. The granulation tissue was divided into healthy (pink in color and does not bleed on probing) and unhealthy granulation tissue (dark red in color and often bleeds on probing). Criteria for dry socket assessment were based on Blum's method. ${ }^{25}$

The degree of inflammation: Inflammation was assessed clinically by gentle probing of the extraction socket to ensure presence or absence of gingival bleeding and recorded as no, mild, moderate, and severe bleeding.

\section{Data collection and Statistical Analysis}

Readings for each parameter was recorded postoperatively on $1^{\text {st }}, 3^{\text {rd }}$, and $7^{\text {th }}$ day. Data from the three groups were collected, tabulated and statistically analyzed using a SPSS statistical package. The data were summarized as means and standard deviations for continuous outcomes (age, difficulty score, pain, mouth opening). ANOVA used to compare between the mean values of the three groups and repeated measures ANOVA used to evaluate the change by time in each group. The data were summarized frequency for qualitative data inflammation and exposed socket wall scores) Chi square test used to compare between the mean values of the three groups. The level of significance was set at 5\% for all statistical analyses and confidence interval at $95 \%$ (95\% CI). The level of significance was concluded at $P<0.05$.

\section{RESULTS}

Out of thirty patients, seventeen were males $(64.4 \%)$ and thirteen were females (35.6\%). Patient age ranged from 18 to 47 years. The mean degree of surgical difficulty was $7.38 \pm 1.22$. Out of 30 patients, 3 patients had dry socket, 2 patients out 
of 3 belong to control group. while single case was among the CHX study group

The sample of ten patients with a mean age of 30 years were included in this study, the age and difficulty score (DS) distribution of the included cases at baseline showed non-statistically significant differences between the three groups table 1 .

TABLE (1): Age and difficulty score (DS) distribution of the patients

\begin{tabular}{|c|c|c|c|c|}
\hline & & Mean & Std. Deviation & $P$ value \\
\hline \multirow[t]{3}{*}{ AGE } & PRF & 30.4 & 9.1433 & \multirow[t]{3}{*}{0.73} \\
\hline & $\mathrm{CHX}$ & 31 & 7.61577 & \\
\hline & Control & 28.5 & 4.55217 & \\
\hline \multirow[t]{3}{*}{ DS } & PRF & 7.8 & 1.47573 & \multirow[t]{3}{*}{0.95} \\
\hline & $\mathrm{CHX}$ & 8 & 1.24722 & \\
\hline & Control & 7.9 & 1.52388 & \\
\hline
\end{tabular}

\section{PAIN SCORE}

Three groups showed statistically significant decrease in pain scores (VAS values) after 1, 3, and 7 days. However, there is statistically significant less pain for PRF group compared to other groups at $3^{\text {rd }}$ and $7^{\text {th }}$ days. (table 2, fig 4)

\section{Inflammation score:}

The three groups showed statistically significant improvement in inflammation score after 1,3, and 7 days. However, there is more improvement for PRF group compared to other groups. On comparison of three groups there is a statistically non-significant difference. table 3 .

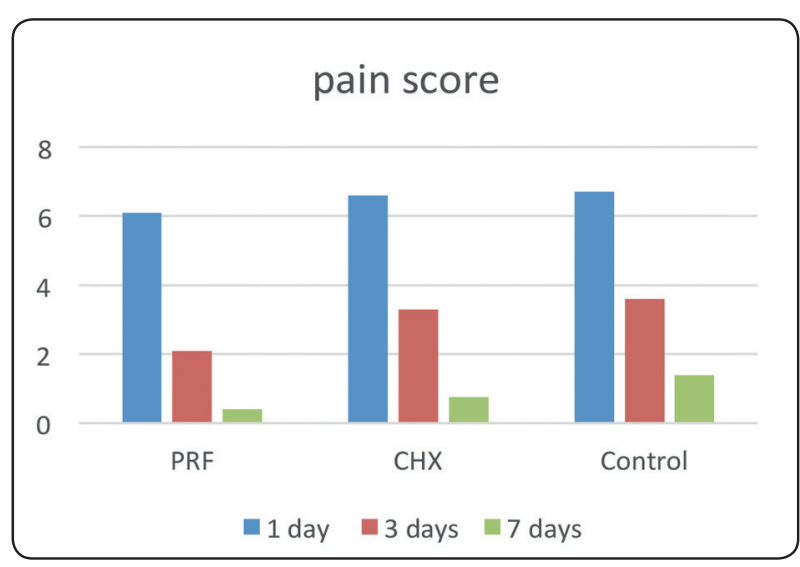

Fig (4): Comparison of pain scores index of patients in three groups

\section{Socket healing}

\section{Exposed socket wall score:}

Regarding Exposed bony socket walls score at $1^{\text {st }}, 3^{\text {rd }}$ and $7^{\text {th }}$ days there are statistically nonsignificant differences between groups. However, there is more improvement for PRF group compared to other groups. table 4 .

\section{Maximum interincisal opening}

The three groups showed statistically significant increase in mouth opening after 1,3, and 7 days. At different follow up periods, there is statistically significant more improvement for PRF group compared to other groups (table 5 , fig 5 ) .

TABLE (2): Pain scores (VAS values) after 1,3, and 7 days of study and control groups

\begin{tabular}{|c|c|c|c|c|c|c|c|}
\hline & \multicolumn{6}{|c|}{ Group } & \multirow{3}{*}{$P$ value } \\
\hline & \multicolumn{2}{|c|}{ PRF } & \multicolumn{2}{|c|}{ CHX } & \multicolumn{2}{|c|}{ Control } & \\
\hline & Mean & Std. Deviation & Mean & Std. Deviation & Mean & Std. Deviation & \\
\hline 1 day & 6.1 & 0.73786 & 6.6 & 0.5164 & 6.7 & 0.82327 & 0.12 \\
\hline 3 days & 2.1 & 0.99443 & 3.3 & 0.94868 & 3.6 & 0.84327 & $0.003^{*}$ \\
\hline 7 days & 0.4 & 0.5164 & 0.75 & 1.3 & 1.4 & 1.17379 & $0.04 *$ \\
\hline$P$ value & \multicolumn{2}{|c|}{$<0.0001^{*}$} & \multicolumn{2}{|c|}{$<0.001 *$} & \multicolumn{2}{|c|}{$<0.001^{*}$} & \\
\hline
\end{tabular}


TABLE (3): Inflammation score after 1, 3, and 7 days for study and control groups

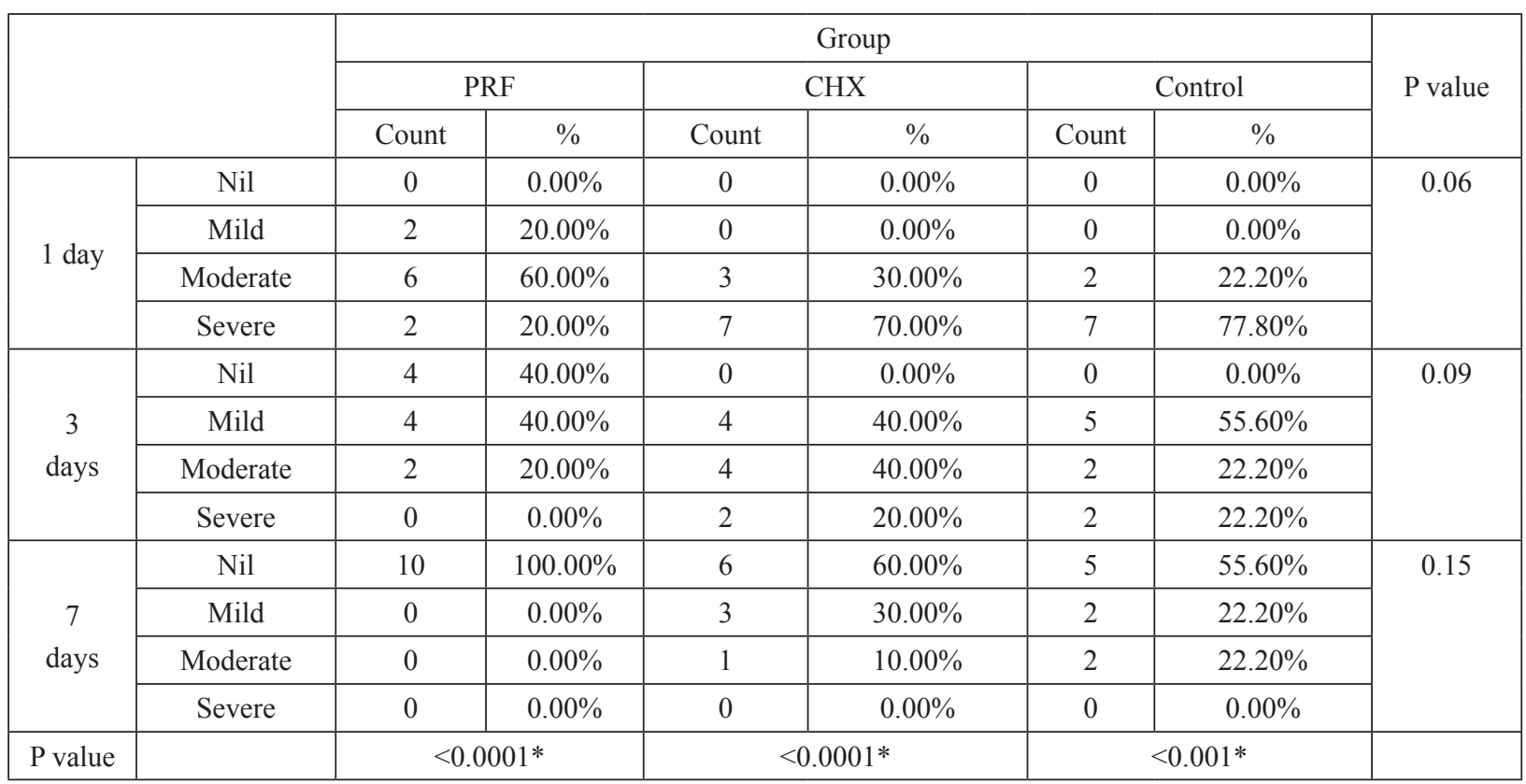

$* P<0.05$ mean statistically significant differences

TABLE (4): socket walls score at first 3rd and 7th days for study and control groups

\begin{tabular}{|c|c|c|c|c|c|c|c|c|}
\hline & \multicolumn{6}{|c|}{ Group } & \multirow{3}{*}{$P$ value } \\
\hline & & \multicolumn{2}{|c|}{ PRF } & \multicolumn{2}{|c|}{ CHX } & \multicolumn{2}{|c|}{ Control } & \\
\hline & & Count & $\%$ & Count & $\%$ & Count & $\%$ & \\
\hline \multirow{5}{*}{$\begin{array}{c}1 \\
\text { day }\end{array}$} & 0 wall & 10 & $100.00 \%$ & 10 & $100.00 \%$ & 8 & $80.00 \%$ & \multirow[t]{5}{*}{0.11} \\
\hline & 1 wall & 0 & $0.00 \%$ & 0 & $0.00 \%$ & 2 & $20.00 \%$ & \\
\hline & 2 walls & 0 & $.0 \%$ & 0 & $.0 \%$ & 0 & $.0 \%$ & \\
\hline & 3 walls & 0 & $.0 \%$ & 0 & $.0 \%$ & 0 & $.0 \%$ & \\
\hline & 4 walls & 0 & $.0 \%$ & 0 & $.0 \%$ & 0 & $.0 \%$ & \\
\hline \multirow{5}{*}{$\begin{array}{c}3 \\
\text { days }\end{array}$} & 0 wall & 7 & $70.00 \%$ & 4 & $40.00 \%$ & 4 & $40.00 \%$ & \multirow[t]{5}{*}{0.55} \\
\hline & 1 wall & 2 & $20.00 \%$ & 3 & $30.00 \%$ & 4 & $40.00 \%$ & \\
\hline & 2 walls & 1 & $10.00 \%$ & 2 & $20.00 \%$ & 0 & $0.00 \%$ & \\
\hline & 3 walls & 0 & $0.00 \%$ & 0 & $0.00 \%$ & 1 & $10.00 \%$ & \\
\hline & 4 walls & 0 & $0.00 \%$ & 1 & $10.00 \%$ & 1 & $10.00 \%$ & \\
\hline \multirow{5}{*}{$\begin{array}{c}7 \\
\text { days }\end{array}$} & 0 wall & 10 & $100.00 \%$ & 7 & $70.00 \%$ & 6 & $60.00 \%$ & \multirow[t]{5}{*}{0.27} \\
\hline & 1 wall & 0 & $0.00 \%$ & 2 & $20.00 \%$ & 2 & $20.00 \%$ & \\
\hline & 2 walls & 0 & $0.00 \%$ & 1 & $10.00 \%$ & 2 & $20.00 \%$ & \\
\hline & 3 walls & 0 & $.0 \%$ & 0 & $.0 \%$ & 0 & $.0 \%$ & \\
\hline & 4 walls & 0 & $.0 \%$ & 0 & $.0 \%$ & 0 & $.0 \%$ & \\
\hline
\end{tabular}


TABLE (5): Maximum interincisal mouth opening for study and control groups

\begin{tabular}{|c|c|c|c|c|c|c|c|}
\hline & \multicolumn{6}{|c|}{ Group } & \multirow{3}{*}{$P$ value } \\
\hline & \multicolumn{2}{|r|}{ PRF } & \multicolumn{2}{|c|}{$\mathrm{CHX}$} & \multicolumn{2}{|c|}{ Control } & \\
\hline & Mean & Std. Deviation & Mean & Std. Deviation & Mean & Std. Deviation & \\
\hline 1 day & 35.5 & 3.97911 & 32.8333 & 32.2 & 31.3 & 4.02906 & $0.042 *$ \\
\hline 3 days & 40.4 & 2.41293 & 37 & 3.39935 & 34.3 & 2.58414 & $<0.0001 *$ \\
\hline 7 days & 45.5 & 2.50555 & 40.5 & 2.3214 & 38.8 & 2.48551 & $<0.0001 *$ \\
\hline$P$ value & \multicolumn{2}{|c|}{$<0.0001 *$} & \multicolumn{2}{|c|}{$<0.001^{*}$} & \multicolumn{2}{|c|}{$<0.001 *$} & \\
\hline
\end{tabular}

$* P<0.05$ mean statistically significant differences

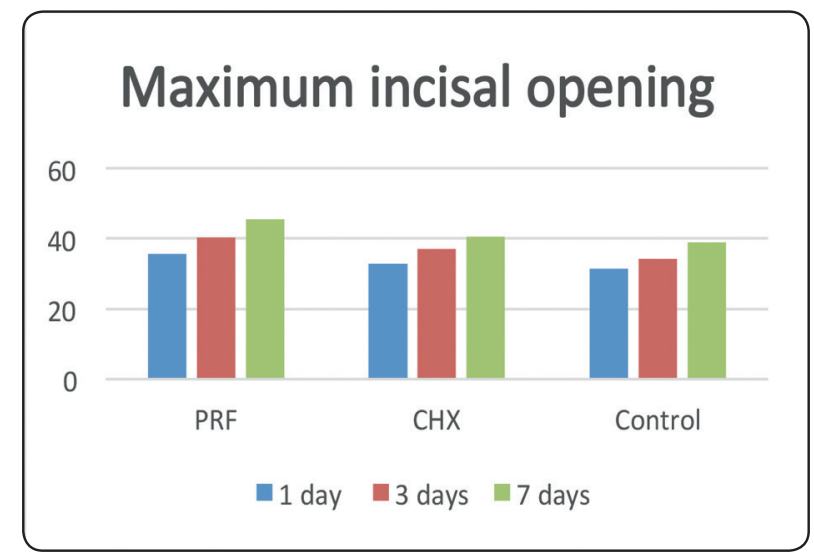

Fig (5): Comparison of Maximal interincisal mouth opening of patients in three groups

\section{DISCUSSION}

Regenerative dentistry is in continuous progress to improve the clinical outcomes and to reduce surgical complications. From this view, there was an attention toward the assessment of a novel technique in post-extraction phase by using the PRF to improve soft tissue healing and to reduce postextraction complications. The key compositions of PRF which enhance the healing process are: the fibrin structure which serving as a supporting matrix for angiogenesis, the platelets which release growth factors that promote regeneration and the presence of leukocytes and stem cells which have (antibacterial, angiogenesis, and regenerative properties). PRF also reported to enhance the coverage of injured tissues through its positive effect on epithelial cells and fibroblasts. Dohan et al. ${ }^{15}$ suggested that PRF can correct destructive reactions in the natural process of healing; Thus PRF has immune regulatory mechanism rather than inflammatory modulation. The present study is an attempt to assess the healing potential of PRF in comparison with CHX. The rationale for using PRF in our study was based on previous studies, which showed the potential of PRF in the process of soft and hard tissue healing. In the present study efficacy of PRF and CHX was evaluated on the basis of capability to provide pain relief and clinical evidence of socket healing.

In this study, PRF and CHX gel had positive effects regarding postoperative pain in the study group compared with control group as shown in Table 2, this reduction in pain level considered statistically to be significant as $\mathrm{P}$ value was 0.003 and 0.04 at $3^{\text {rd }}$ and $7^{\text {th }}$ day respectively. This was in agreement with a study published by Singh et $\mathrm{al}^{22}$. The results of the present study disagree with Ozgul et $\mathrm{al}^{26}$. Current study revealed that PRF significantly reduced postoperative pain following surgical removal of impacted third molars. This could reflect a better healing of the extraction sockets. VAS scores for pain improved gradually during the follow-up period and the intensity of 
pain decreased in study groups over a period of time. This decrease was significantly more in PRF group (Table 2, Fig 4). Reductions in pain level by the use of PRF might be due to PRF action as an immune regulator and may decrease the deleterious effects of inflammation as described by the Dohan et al. ${ }^{21}$ It has been suggested that the fibrin matrix results in angiogenesis, therefore it provides natural resurfacing of the socket wound, which results in the covering of the exposed nerve endings in the socket leading to a marked decrease of associated pain.

PRF and CHX gel enhanced the quality of soft tissue healing as recorded by (healing index of Landry et $\mathrm{al}^{24}$ ) and reduced signs of inflammatory process including (bleeding) within the study group compared with control group at the 3rd. and 7th day after extraction. However, there is more improvement for PRF group compared to CHX group. This was in coincidence with a study published by Marenzi et $\mathrm{al}^{27}$ and Kumar et $\mathrm{al}^{28}$. Platelet-rich fibrin and CHX gel showed positive effects on acceleration of epithelialization among study group compared with control group but it was statistically non-significant as $P$ value equaled 0.27 (Table 4) at the 1st week after extraction.

In this study, alveolar osteitis AO was developed in 2 patients among control group 20\% while it was $10 \%$ and $0 \%$ for CHX \& PRF respectively among study group, but this was not statistically significant to prove the effects of PRF on dry socket prevention. PRF is a healing biomaterial; perhaps this could explain the significant difference in the incidence of $\mathrm{AO}$ encountered in the PRF group compared with the control group. The positive role of PRF in the prevention of AO was also reported by Hoaglin and lines ${ }^{29}$ and Eshghpour et $\mathrm{al}^{30}$. It has been reported that PRF can act as scaffolding and reservoirs for angiogenic factors during the woundhealing period.

Regarding measures to prevent post-extraction complications our results are similar to Abu-
Mostafa et al ${ }^{31}$, Haraji and Rakhshan ${ }^{32}$, Barbar et $\mathrm{al}^{33}$ that noted the positive effect of $0.2 \%$ chlorhexidine and reported that $0.2 \% \mathrm{CHX}$ gel was a good prophylactic agent and it can reduce edema and AO incidence where it applied in the intra-alveolar site after impacted third molar removal regarding the effectiveness of a single-dose of intra-alveolar placement of $0.2 \%$ CHX gel. Requena-Calla and Funes-Rumiche ${ }^{18}$ reported no relationship between CHX gel and the reduction of AO incidence. The bio-adhesive $0.2 \%$ chlorhexidine gel could improve the action of chlorhexidine since placement of chlorhexidine gel directly into the socket will allow a more direct action on the alveolus, and also we can see the long lasting effect of the gel placed. $0.2 \%$ chlorhexidine bioadhesive gel was impregnated on dressings of gelatin sponge and pushed gently into the sockets. The compressive effect on the alveolar walls may facilitate bleeding cessation as well as the hemostatic effect of gelatin sponge.

In our study alveolar socket healing was better in PRF group as compared to CHX and control groups at the $3^{\text {rd }}$ and $7^{\text {th }}$ post-treatment days. PRF showed much better results with improved socket healing and reduced inflammation, effective pain control, along with being more economical, compared to CHX. Exposed bony walls in extraction sockets showed better healing with granulation tissue formation at day 3 and 7 and coverage of healthy granulation tissue post-operatively, after being treated with PRF (Fig 2D). This is attributing PRF has a slow continuous release of growth factors for at least seven. PRF as a filling material in extraction socket; clinically it has been confirmed the neovascularization and epithelial coverage of the extraction socket. PRF contains platelets and plasma rich in growth factors, copious amount of growth factors such as platelet-derived growth factor (PDGF), platelet-derived endothelial growth factor (PDEGF), platelet-derived angiogenesis factor (PDAF), transforming growth factor beta (TGF-b), and epidermal growth factor (EGF) liberated from 
PRF network; these factors play an essential role fibroblasts recruitment, increased angiogenesis, tissue reconstitution, and finally covering of the wound. These factors enhance granulation tissue production and epithelialization.

On the basis of clinical evaluation and statistical analysis we found that in patients where intra alveolar chlorhexidine gel or PRF was placed there was significant reduction in pain on the 3 rd postoperative day and 7th post-operative day. Mouth opening was also good post-operatively when compared with control group. In statistical analysis, the probability value ( $P$ value) for mouth opening, in overall comparison of study and control groups was less than 0.05 (Table 5\&Fig 5) which prove it to be statistically significant. From this it can be concluded that both chlorhexidine gel and PRF is effective in reducing post-extraction complications such as trismus but PRF is more effective.

In our observation, we found that patients were maximally benefited by the placement of PRF as none of the patients in this group reported with alveolar osteitis. In this study, three patients developed dry socket, for two patients in control group, and for one patient in chlorhexidine gel group were detected. The results from this study showed that PRF promoted the quality of soft tissue healing at the 1st week after surgical extraction. PRF are clearly showing optimistic improvement in clinical signs. However, further studies with larger sample size are necessary.

\section{CONCLUSION}

This study indicates that both chlorhexidine gel and PRF are effective in reducing post-operative complications which are pain, inflammation, reduction in mouth opening and dry socket. This improvement signifies and highlights the use of chlorhexidine gel and PRF in the prevention of alveolar osteitis after extraction of mandibular third molar. The limitation of the present study is reduced sample size. In our study, we found that
PRF has appropriate affirmative outcomes. The results of this study showed that (PRF) has good pain control with good epithelisation of the socket and better clinical socket healing with reduction of inflammation. Within the limitations of the present study, platelet-rich fibrin (PRF) application after mandibular third molar surgery is a good biologic material that reduces postoperative complications such as alveolar osteitis.

\section{REFERENCES}

1. Araújo MG, Silva CO, Misawa M, Sukekava F. Alveolar socket healing: what can we learn? Periodontol 2000; 68:122-34, 2015 .

2. Asmael HM, Jamil FA, Hasan AM. Novel application of Platelet-Rich Fibrin as a wound healing enhancement in extraction sockets of patients who smoke. J Craniofac Surg.;29: 794-797, 2018

3. Choukroun J, Diss A, Simonpieri A, Girard MO, Schoeffler C, Dohan SL et al. Platelet-rich fibrin (PRF): a secondgeneration platelet concentrate. Part IV: clinical effects on tissue healing. Oral Surg Oral Med Oral Pathol Oral Radiol Endod; 101:56-60, 2006.

4. Blum IR. Contemporary views on dry socket (alveolar osteitis): a clinical appraisal of standardization, aetiopathogenesis and management: a critical review. Int $\mathrm{J}$ Oral Maxillofac Surg; 31(3):309-17, 2002.

5. Saghiri MA,Asatourian A,3 and Sheibani N.Angiogenesis and the prevention of alveolar osteitis: a review study.J Korean Assoc Oral Maxillofac Surg.; 44: 93-102, 2018.

6. Parthasarathi K, Smith A. , Chandu A.: Factors affecting incidence of dry socket: a prospective community-based study. J Oral Maxillofac Surg. ; 69:1880-4, 2011.

7. Fernandes GJ, Hatton MN. Prevention of alveolar osteitis. A case report and review of literature. N Y State Dent J.; $82: 21-25,2016$

8. Wates E, Ria B. The prevention and management of dry socket. Do antibiotics have a role to play? Prim Dent J.; $4: 42-43,2015$

9. Mamoun J.; Dry Socket Etiology, Diagnosis, and Clinical Treatment Techniques. J Korean Assoc Oral Maxillofac Surg.; 44:52-58. 2018.

10. Tarakji B, Saleh LA, Umair A, Azzeghaiby SN, Hanouneh S. Systemic review of dry socket: aetiology, treatment and prevention. J Clin Diagn Res.; 9:10, 2015. 
11. Jesudasan JS, Wahab PU, Sekhar MR. Effectiveness of $0.2 \%$ chlorhexidine gel and eugenol based paste on postoperative alveolar osteitis in patients having third molars extracted: a randomized controlled clinical trial. $\mathrm{Br}$ J Oral Maxillofac Surg.; 53:826-830, 2015.

12. Haraji A, Lassemi E, Motamedi M, Alavi M, Adibnejad S. Effect of plasma rich in growth factors on alveolar osteitis. Natl J Maxillofac Surg.; 3:38-41, 2012.

13. Dohan DM, Choukroun J, Diss A, Dohan SL, Dohan AJ, Mouhyi $\mathrm{J}$ et al. Platelet-rich fibrin (PRF): a second generation platelet concentrate, Part I: technological concepts and evolution. Oral Surg Oral Med Oral Pathol Oral Radiol Endod; 101:37-44, 2006.

14. Dohan DM, Choukroun J, Diss A, Dohan SL, Dohan AJ, Mouhyi J et al. Platelet-rich fibrin (PRF): a second-generation platelet concentrate. Part II: platelet related biologic features. Oral Surg Oral Med Oral Pathol Oral Radiol Endod; 101:45-50. 2006

15. Dohan DM, Choukroun J, Diss A, Dohan SL, Dohan AJ, Mouhyi J et al. Platelet-rich fibrin (PRF): a second generation platelet concentrate. Part III: leucocyte activation: a new feature for platelet concentrates. Oral Surg Oral Med Oral Pathol Oral Radiol Endod;101:51-5,2006

16. Al-Hamed FS, Tawfik M A and Abdelfadil E. Clinical effects of platelet-rich fibrin (PRF) following surgical extraction of lower third molar. The Saudi Journal for Dental Research; 8:19-25, 2017.

17. Asutay F, Yolcu Ü, Geçör O, Acar AH, Öztürk SA, and Malkoç S. An evaluation of effects of platelet-rich-fibrin on postoperative morbidities after lower third molar surgery. Niger J Clin Pract; 8, IP: 197.42.200.234, 2019.

18. Requena-Calla S, Funes-Rumiche. Effectiveness of intraalveolar chlorhexidine gel in reducing dry socket following surgical extraction of lower third molars. A pilot study. J Clin Exp Dent. ; 8: 160-163 2016.

19. Teshome A. The efficacy of chlorhexidine gel in the prevention of alveolar osteitis after mandibular third molar extraction: a systematic review and meta-analysis. BMC Oral Health; 17:82, 2017.

20. TZhou J1, Hu B1, Liu Y1, Yang Z1, Song J. The efficacy of intra-alveolar $0.2 \%$ chlorhexidine gel on alveolar osteitis: a meta-analysis. Oral Dis. ; 23(5):598-608, 2017.

21. Shad S, Hussain SM, Tahir MW, Rahat Geelani SR, Khan SM, Abbasi MM. Role of $0.2 \%$ bio-adhesive chlorhexidine gel in reducing incidence of alveolar osteitis. J Ayub Med Coll Abbottabad; 30:524-528, 2018.

22. Singh M. Incidence etiology and treatment of alveolar osteitis. Int J Recent Adv Multidiscip Res; 3:1167-70. 2016.
23. Bali A, Bali D, Sharma A, Verma G.Is pederson index a true predictive difficulty index for impacted mandibular third molar surgery? A meta-analysis. J Maxillofac Oral Surg.; 12:359-64, 2013.

24. Landry RG, Turnbull RS, Howley T. Effectiveness of benzydamine $\mathrm{HCl}$ in the treatment of periodontal post-surgical patients. Res Clin Forums, 10:105-18, 1988.

25. Blum IR. Contemporary views on dry socket (alveolar osteitis): a clinical appraisal of standardization, aetiopathogenesis and management: a critical review. Int J Oral Maxillofac Surg; 31(3):309-17, 2002.

26. Ozgul O, Senses F, Er N, Tekin U, Tuz HH, Alkan A, Koçyiğit ID, Atıl F. Efficacy of platelet rich fibrin in the reduction of the pain and swelling after impacted third molar surgery: Randomized multicenter split-mouth clinical trial. Head Face Med; 11:37-41, 2015.

27. Marenzi G, Riccitiello F, Tia M, di Lauro A, Sammartino G. Influence of leukocyte- and platelet-rich fibrin (L-PRF) in the healing of simple postextraction sockets: a splitmouth study. BioMed Res Int; ID 369273, 2014.

28. Kumar N, Prasad K, Ramanujam L, K R, Dexith J, Chauhan A. Evaluation of treatment outcome after impacted mandibular third molar surgery with the use of autologous platelet-rich fibrin: a randomized controlled clinical study. J Oral Maxillofac Surg;73:1042-9, 2015.

29. Hoaglin Donald R, Lines Gary K. Prevention of localized osteitis in mandibular third-molar sites using platelet-rich fibrin. Int J Dent; ID 875380. 2013.

30. Eshghpour M, Dastmalchi P, Nekooei AH, Nejat A. Effect of platelet-rich fibrin on frequency of alveolar osteitis following mandibular third molar surgery: a double-blinded randomized clinical trial. J Oral Maxillofac Surg; 72:1463$7,2014$.

31. Abu-Mostafa NA, Alqahtani A, Abu-Hasna M, Alhokail A, Aladsani A. A randomized clinical trial compared the effect of intra-alveolar $0.2 \%$ Chlorohexidine bio-adhesive gel versus $0.12 \%$ Chlorohexidine rinse in reducing alveolar osteitis following molar teeth extractions. Med Oral Patol Oral Cir Bucal. ; 20:82-7. 2015.

32. Haraji A, Rakhshan V. Single-dose intra-alveolar chlorhexidine gel application, easier surgeries, and younger ages are associated with reduced dry socket risk. J Oral Maxillofac Surg.; 72:259-65, 2014.

33. Babar A, Ibrahim MW, Baig NJ, Shah I, Amin E. Efficacy of intra-alveolar chlorhexidine gel in reducing frequency of alveolar osteitis in mandibular third molar surgery. J Coll Physicians Surg Pak.; 22:91-4, 2012. 